\title{
Comentarios a la Ley General de Turismo de Colombia tras la reforma del año $2012\left({ }^{1}\right)$
}

\author{
María Matilde Ceballos Martín \\ Profesora Titular de Derecho Administrativo \\ Universidad Oberta de Cataluña \\ Universidad de Almería \\ Email: mceballo@ual.es \\ Raúl Pérez Guerra \\ Profesor Titular de Derecho Administrativo \\ Universidad Oberta de Cataluña \\ Universidad de Almería \\ Email: rperez@ual.es
}

Resumen: El artículo realiza un análisis crítico de la reciente reforma llevada a cabo en Colombia en la Ley General de Turismo. Para ello se lleva a cabo un estudio básico de los principios fundamentales de dicha Ley, así como un repaso por su incidencia en el ámbito administrativo y fiscal

Palabras Clave: Derecho, turismo, Colombia, administrativo, incentivos, fiscalidad

Abstract: The article provides a critical analysis of the recent reform carried out in Colombia in the General Law on Tourism. This will perform a basic study of the fundamental principles of that law, as well as a review of their impact on the administrative and fiscal

Key Words: Law, tourism, Colombia, administrative, incentives, tax

\footnotetext{
1 El presente trabajo se realiza en el marco del Grupo de Investigación SEJ-200 "Derecho Público y Privado de la Agroalimentación y de la Innovación Tecnológica" de la Universidad de Almería, perteneciente al área temática "Ciencias Sociales, Económicas y Jurídicas" del Plan Andaluz de Investigación.
} 


\section{Principios fundamentales de la Ley e instrumentos de planificación de la actividad turística.}

La Ley 300 de 1996, de Turismo de Colombia, considera la actividad turística como una industria esencial para el desarrollo del país, cumpliendo además una función social, por lo que el Estado le dará una protección especial en razón de su importancia para el desarrollo nacional. Como plasmación de esta especial protección, las tasas aplicables a los prestadores de servicios turísticos en materia impositiva serán las que correspondan a la actividad industrial o comercial cuando les sean más favorables (artículo $\left.1^{\circ}\right)$.

Esta norma pivota en torno a varios principios rectores, que inspirarán todo su contenido: concertación, coordinación, descentralización, planeación, libertad de empresa, fomento, facilitación, desarrollo social, económico y cultural, desarrollo sostenible, calidad, competitividad, accesibilidad y protección al consumidor ${ }^{2}$.El legislador colombiano concibe el sector turístico como una actividad económica en la que convergen tres actores principales: el sector oficial (el Ministerio del ramo, las Entidades Territoriales, Prosocial ${ }^{3}$ y demás entidades públicas que tengan asignadas funciones relacionadas con el turismo, con los turistas o con la infraestructura), el sector mixto (integrado por el Consejo Superior de Turismo, el Consejo de Facilitación Turística y el Comité de Capacitación Turística) y el sector privado (conformado por los

\footnotetext{
${ }^{2}$ Debiendo entenderse el principio de concertación como aquél en virtud del cual las decisiones y actividades del sector se socializaran en acuerdos para asumir responsabilidades, esfuerzos y recursos entre los diferentes agentes comprometidos, tanto del sector estatal como del sector privado nacional e internacional para el logro de los objetivos comunes que beneficien el turismo; y el principio de facilitación como aquél en virtud del cual los distintos organismos relacionados directa 0 indirectamente con la actividad turística, simplificarán y allanaran los trámites y procesos que el consejo superior de turismo identifique como obstáculos para el desarrollo del turismo (art. 2).

${ }^{3}$ La Promotora de Vacaciones y Recreación Social (Prosocial) nació en 1973 como un organismo público con el objetivo de financiar obras y planes destinados a proporcionar descanso adecuado durante las vacaciones y sana recreación a la clase trabajadora del país. Desaparecida a causa de sus problemas financieros.
} 
prestadores de servicios turísticos, sus asociaciones gremiales y las formas asociativas de promoción y desarrollo turístico) $)^{4}$.

La primacía en la iniciativa pública en materia de turismo la ostenta el Ministerio de Desarrollo Económico, si bien muestra su interés en que los demás entes territoriales participen en la consecución de los fines expuestos por la Ley de turismo, pero siempre bajo su coordinación y planificación, actividad esta última que se desarrolla fundamentalmente a través del Plan Nacional de Desarrollo y del Plan Sectorial de Turismo. El primero es un instrumento de planificación económica y social de carácter genérico, al tratarse del instrumento legal por medio del cual se dan a conocer los objetivos de gobierno del Presidente de Colombia y su gestión, y además, permite evaluar sus resultados ${ }^{5}$.

Por lo que respecta al Plan Sectorial de Turismo ${ }^{6}$, como parte integrante del Plan Nacional de Turismo, es elaborado por el Vice ministerio de Turismo, perteneciente al Ministerio de Comercio, Industria y Turismo, con base en las líneas estratégicas formuladas $^{7}$, fruto del consenso con los principales actores de la actividad turística nacional ${ }^{8}$.Su objetivo es el desarrollo de productos turísticos específicos. En tal sentido, el legislador colombiano muestra un especial interés por la promoción de ciertas categorías turísticas, obligando a que estos instrumentos de planificación contengan directrices y programas de apoyo específico en materia de ecoturismo, etnoturismo,

\footnotetext{
${ }^{4}$ Junto a estos tres sectores coexiste el subsector de la educación turística formal, en sus modalidades técnica, tecnológica, universitaria, de postgrado y de educación continuada, considerado como soporte del desarrollo turístico y de su competitividad, por lo que merece una atención preferente para su fortalecimiento y participación.

${ }^{5}$ La base de este plan está constituida por las propuestas de campaña presentadas por los candidatos a la Presidencia del Gobierno ante la Registraduría Nacional del Estado Civil en el momento de su inscripción como candidato, conocidas como el programa de gobierno. Su duración coincide con la legislatura del Presidente del Gobierno (cuatro años).

${ }^{6}$ El Plan Sectorial de Turismo vigente en la actualidad es el correspondiente al periodo 20112014, denominado "Turismo: factor de prosperidad para Colombia". Su antecesor fue el correspondiente al periodo 2008-2010, titulado "Colombia: destino turístico de clase mundial".

${ }^{7}$ Las líneas estratégicas para este periodo son el fortalecimiento de la institucionalidad y la gestión pública del turismo a nivel nacional y regional, la mejorara de la calidad de los servicios y destinos turísticos y la promoción de la formalización, el fortalecimiento de las habilidades y competencias del talento humano en función de las necesidades de la demanda turística y la generación de empleo, la mejorara de la gestión en infraestructura de soporte y conectividad para el turismo, el impulso a la inversión en el sector turístico, buscando la generación de valor agregado nacional; el fortalecimiento del desarrollo de productos turísticos especializados y el enfoque de las iniciativas de promoción turística por segmentos especializados del turismo.

${ }^{8}$ Incluyendo la participación ciudadana a través de una consulta pública.
} 
agroturismo, acuaturismo y turismo metropolitano ${ }^{9}$, en coordinación con el Ministerio de Medio Ambiente ${ }^{10}$.

Junto a estos instrumentos principales se recogen los denominados Planes Sectoriales de Desarrollo Departamentales, Distritales y Municipales, a cargo de los diferentes Departamentos, Regiones, el Distrito Capital de Santa Fe de Bogotá, los Distritos y Municipios y las comunidades indígenas en sus respectivas jurisdicciones. Todos deben seguir las directrices básicas contenidas en el Plan Sectorial de Turismo, constituyendo su desarrollo específico a nivel regional y local.

A nivel de promoción turística en el exterior, se prevé la posibilidad de realizar convenios con la representación nacional en el extranjero para realizar estas actividades con cargo al Fondo de Promoción Turística, del que se hablará a continuación. En tal sentido, se prevé igualmente la elaboración de un Plan de Mercadeo y Promoción Turística para el Turismo Doméstico e Internacional ${ }^{11}$.

\section{El Fondo de Promoción Turística.}

\footnotetext{
${ }^{9}$ La reforma operada recientemente en esta norma por la Ley 1.558 de 2012 , de 10 de julio, generaliza los estándares de calidad exigidos hasta entonces a las actividades relacionadas con el turismo de aventura y la sostenibilidad turística a la totalidad de prestadores turísticos, de acuerdo con el desarrollo reglamentario a cargo del Ministerio del ramo.

${ }^{10}$ La Ley de turismo colombiana garantiza la primacía de la Administración medioambiental sobre aquellos proyectos turísticos que incidan sobre espacios valiosos desde el punto de vista de la preservación de los recursos naturales. Así, el artículo 27 señala que "[...] cuando quiera que las actividades ecoturísticas que se pretendan desarrollar en áreas del Sistema de Parques Nacionales Naturales, serán estas entidades [Ministerio de Medio Ambiente] las que definan la viabilidad de los proyectos, los servicios que se ofrecerán, las actividades permitidas, capacidad de carga y modalidad de operación". Además, "En aquellas áreas naturales de reserva o de manejo especial, distintas al Sistema de Parques que puedan tener utilización turística, el Ministerio del Medio Ambiente definirá, conjuntamente con las autoridades de turismo, las regulaciones, los servicios, las reglas, convenios y concesiones de cada caso, de acuerdo con la conveniencia y compatibilidad de estas áreas",

${ }_{11}$ Actualmente existe un instrumento de planeamiento denominado "Política de mercadeo y promoción turística de Colombia", elaborado en 2009 en el marco del Plan Nacional de Desarrollo "Estado Comunitario: desarrollo para todos" y del Plan Sectorial de Turismo 20082010 "Colombia Destino de clase mundial". Su objetivo primordial es lograr la eficacia en las acciones de promoción y mercadeo de los destinos y productos turísticos de Colombia, de manera que logre generar un crecimiento del número de viajeros nacionales e internacionales, posicionando al país como un destino competitivo. Para alcanzar este objetivo cuenta con un catálogo de líneas estratégicas: fortalecimiento de la investigación de destinos turísticos, diferenciación y promoción de productos turísticos prioritarios, fortalecimiento de las actividades y herramientas de promoción turística, fortalecimiento de la promoción turística y articulación interinstitucional para el fortalecimiento de los mecanismos de mercadeo y promoción.
} 
El Fondo de Promoción Turística, regulado en el nuevo artículo 42 de la Ley de turismo colombiana, se configura como un instrumento para la gestión de los recursos provenientes de la contribución parafiscal en materia turística-que será analizada en un epígrafe posterior- y cuya finalidad es la ejecución de proyectos de competitividad, promoción y mercadeo con el fin de incrementar el turismo interno y receptivo de Colombia $^{12}$. Este instrumento también tendrá otros objetivos específicos, como la financiación de políticas de prevención y campañas para la erradicación del turismo asociado a prácticas sexuales con menores de edad.

Los recursos de este fondo se componen fundamentalmente de lo recaudado con la contribución parafiscal con destino a la promoción y competitividad del turismo, que será analizada en un epígrafe especifico, a lo que se añaden otros recursos de carácter secundario $^{13}$ :

a) Los activos adquiridos con los recursos de la contribución parafiscal.

b) Las donaciones.

c) Los recursos provenientes de patrocinios y actividades comerciales.

d) Los recursos derivados de la explotación económica de los activos que fueron de propiedad de la Corporación Nacional de Turismo, en los términos de la reglamentación que para el efecto expida el Ministerio de Comercio Industria y Turismo.

e) Los recursos que provengan de la cooperación internacional en materia de turismo y cualquier otro recurso que se canalice a través de tesorería.

f) Los rendimientos financieros que se deriven del manejo de las anteriores partidas.

g) Los demás activos recibidos para el desarrollo de sus funciones.

\footnotetext{
${ }^{12}$ En cualquier caso, los procesos de contratación que lleve a cabo la Entidad administradora del Fondo de Promoción Turística se adelantarán de conformidad con el Derecho privado.

${ }^{13}$ Conforme al art. 8 de la Ley 1.101 de 2006, de 22 de noviembre, por la cual se modifica la Ley 300 de 1996 -Ley General de Turismo-y se dictan otras disposiciones
} 
Por lo que se refiere a su gestión, la Ley de turismo prevé la posibilidad de que el Ministerio del ramo celebre contratos para la administración de este Fondo con el sector turístico privado más representativo a nivel nacional. Su gestión ordinaria corresponderá en todo caso a un Comité Directivo compuesto por diez miembros ${ }^{14}$, requiriendo el voto favorable del Ministerio de Comercio, Industria y Turismo para la adopción de acuerdos en su seno ${ }^{15}$. El Fondo de Promoción Turística se configura como el principal instrumento para la financiación de las políticas públicas en materia turística, conformando el recurso económico más importante para la efectiva puesta en práctica de estrategias elaboradas por el sector público para esta actividad, como habrá ocasión de comprobar a lo largo de este breve estudio.

\section{La estructuración territorial del turismo: recursos turísticos de utilidad} pública, Zonas de Desarrollo Turístico Prioritario y Círculos Metropolitanos

\section{Turísticos.}

El Ministerio de Desarrollo Económico, previa consulta al Consejo Superior de Turismo, podrá solicitar a los Concejos Distritales o Municipales la declaratoria como “recursos turísticos de utilidad pública” aquellas zonas urbanas o rurales, plazas, vías, monumentos, construcciones y otros que deban desarrollarse con sujeción a planes

\footnotetext{
${ }^{14}$ Que serán (art. 46 de la Ley General de Turismo): a) El Ministro de Comercio, Industria y Turismo quien sólo podrá delegar en el viceministro del ramo. El representante del Ministerio de Comercio, Industria y Turismo presidirá el Comité; b) El Presidente de Proexport o su delegado; c) Cinco representantes de organizaciones gremiales de aportantes; d) Un gobernador designado por la Conferencia de Gobernadores; e) Un alcalde designado por la Federación Colombiana de Municipios; f) Un representante del sector de ecoturismo. Además, a las reuniones del Comité Directivo del Fondo será invitado el Director del Instituto Colombiano de Bienestar Familiar, cuando quiera que se discuta la destinación de recursos para la ejecución de políticas de prevención y campañas para la erradicación de turismo asociado a prácticas sexuales con menores de edad.

${ }^{15}$ Las funciones del Comité Directivo son (art. 47 de la Ley General de Turismo): a) Aprobar el presupuesto anual de ingresos y gastos del Fondo presentado por la Entidad Administradora del mismo, previo visto bueno del Ministerio de Desarrollo Económico; b) Aprobar las inversiones que con recursos del Fondo deba llevar a cabo la Entidad Administradora para cumplir con el contrato de administración del mismo; c) Velar por la correcta y eficiente gestión del Fondo por parte de la Entidad Administradora del mismo.
} 
especiales, adquirirse por el Estado o preservarse, restaurarse o reconstruirse ${ }^{16}$. La declaración de un bien como recurso turístico, del que deberá existir un inventario público, y cuya administración y explotación se podrá delegar a particulares mediante contratación o concesión, tendrá los siguientes efectos:

a) El bien objeto de la declaratoria estará especialmente afectado a su explotación como atractivo turístico nacional o regional, con prioridad a su utilización frente a otros fines distintos y contrarios a la actividad turística.

b) Cuando el bien objeto de la declaratoria sea público, deberá contar con un programa y un presupuesto de reconstrucción, restauración y conservación a cargo del presupuesto de la entidad territorial en cuya jurisdicción se encuentre ubicado $^{17}$.

El citado inventario de recursos turísticos de utilidad pública deberá ser elaborado por el Ministerio de Desarrollo Económico en un plazo máximo de seis meses contados a partir de la vigencia de la presente, a partir del cual podrán definirse los programas de promoción turística que se elaboren.

Por su parte, a los entes distritales y municipales -previo el visto bueno del Ministerio de Comercio, Industria y Turismo o a solicitud de éste-, les corresponde la determinación de las llamadas "Zonas de Desarrollo Turístico Prioritario"18, que tendrán los siguientes efectos:

\footnotetext{
${ }^{16}$ Sólo podrán hacerse declaratorias de recursos turísticos en los Territorios indígenas y en las comunidades negras, previo consentimiento de las respectivas comunidades que tradicionalmente los habitan, de acuerdo con los mecanismos señalados por la Ley para tal efecto (art. 23.1).

${ }^{17}$ En caso que la declaratoria de recurso turístico haya sido solicitada por el Ministerio de Desarrollo Económico, los recursos para su reconstrucción, restauración y conservación estarán a cargo del Presupuesto Nacional, para lo cual el Ministerio de Desarrollo Económico gestionará la inscripción del proyecto en el Banco de Proyectos de Inversión Nacional y su aprobación por parte del Departamento Nacional de Planeación (art. 24.2).

${ }_{18}$ Junto con estos espacios coexisten las llamadas "Zonas Francas Turísticas", reguladas por el Decreto 2.131 de 1991. Conforme a esta norma, debe entenderse por Zona Franca Industrial de Servicios Turísticos -que en adelante se denominará "Zona Franca Turística"-, aquélla área geográfica delimitada del territorio nacional, con el objeto primordial de promover y desarrollar la prestación de servicios en la actividad turística, destinados al turismo receptivo y de manera subsidiaria al turismo nacional. En estas zonas se permitirá la realización de aquéllas
} 
a) Afectación del uso del suelo para garantizar el desarrollo prioritario de actividades turísticas. El uso turístico primará sobre cualquier otro uso que más adelante se decrete sobre tales áreas, y que no sea compatible con la actividad turística.

b) Apoyo local en la dotación a esas áreas de servicios públicos e infraestructura básica, de acuerdo con los planes maestros distritales o municipales.

c) Posibilidad de que los Concejos Distritales o Municipales establezcan exenciones sobre los tributos de su competencia en estas zonas.

d) Posibilidad de apoyo por parte del Ministerio de Comercio, Industria y Turismo a través de acciones de promoción y competitividad.

A pesar de la regulación reglamentaria de estas zonas, la Ley General de Turismo crea un órgano para la determinación de sus políticas de promoción, funcionamiento y control de las mismas: el Comité de Zonas Francas. Está compuesto por el Ministro de Comercio Exterior (quien lo presidirá y podrá delegar su representación en el Viceministro), el Ministro de Desarrollo Económico, el Ministro de Hacienda, el Director de la Dirección de Impuestos y Aduanas Nacionales (DIAN) y el Director del

actividades turísticas consideradas como tales por el propio Decreto: la prestación de servicios de alojamiento, de agencias de viajes, restaurantes, organizaciones de congresos, servicios de transporte, actividades deportivas, artísticas, culturales, y recreacionales; así como la venta de mercancías al por menor a través de los almacenes autorizados a particulares por el usuario operador, que en todo caso deberá respetar la legislación aduanera vigente. En cuanto a las condiciones especiales que esta norma prevé para las Zonas Francas Turísticas destacan el cobro, dentro de las mismas, del impuesto al turismo establecido por el Decreto no 272 de 1957; se podrán introducir en las mismas, sin abonar los derechos de importación, vehículos a motor con un número de plazas superior a ocho, que únicamente podrán transitar en la Zona Franca y entre ésta y el puerto o aeropuerto o el terminal de transporte, con el objeto de transportar los turistas destinados a la Zona Franca; también se podrán introducir en estas zonas, sin el pago de derechos de importación, naves como yates, veleros y vapores con la finalidad de transportar turistas o de cualquier otro servicio turístico (así como la posibilidad de introducir temporalmente las naves de los turistas); y las empresas de transporte aéreo comercial podrán realizar, sin limitaciones de número de vuelos, servicios de transporte internacional no regular en los aeropuertos que sirvan a las Zonas Francas Turísticas. La superficie mínima de estas zonas serán cincuenta hectáreas $(500.000$ m²). 
Departamento Nacional de Planeación, o sus respectivos delegados. Sus funciones serán estudiar y emitir concepto sobre las solicitudes de zona franca presentadas a su consideración por el Ministerio de Comercio Exterior, analizar y proponer las políticas de funcionamiento y promoción de las zonas francas y los mecanismos de control de las mismas, y emitir concepto sobre las solicitudes de ampliación o reducción de las zonas francas ${ }^{19}$.

Las últimas entidades territoriales de base turística previstas por la Ley General de Turismo de Colombia-modificada recientemente por la Ley 1.558 de 2012, de 10 de julio-son los denominados “Círculos Metropolitanos Turísticos”, entidades asociativas para la integración interlocal con el objetivo de mejorar la prestación de servicios turísticos mediante técnicas de cooperación. En tal sentido, la Ley de turismo habilita a los municipios para que voluntariamente conformen Círculos Turísticos con la finalidad específica de promover y desarrollar el turismo en sus regiones respectivas, sin otro requisito que el cumplimiento de las exigencias contenidas en la Ley 1454 de 2011, de Ordenamiento Territorial ${ }^{20}$. La forma de operar de estos entes será mediante la formulación de proyectos al Banco de Proyectos al Fondo Nacional de Turismo, que financiará aquéllos que considere más ventajosos.

Por otro lado, la Ley colombiana señala expresamente que los vehículos de servicio público terrestre automotor individual de pasajeros en Vehículos Taxi que transporten turistas dentro de los Círculos Metropolitanos no requerirán planillas $^{21}$ para trasladarlos entre los municipios que formen parte del correspondiente Círculo, facilitando el transporte de turistas entre aquéllos.

\footnotetext{
${ }^{19}$ En cualquier caso, para coordinar acciones con el sector privado, la Ley permite al Comité de Zonas Francas reunirse de forma periódica con los empresarios del sector. Los empresarios del sector turístico estarán representados por el Consejo Superior de la Microempresa y de la Pequeña y Mediana Empresa, órgano creado por la propia Ley General de Turismo.

${ }^{20}$ En la redacción de la Ley General de Turismo anterior a 2012 se preveía la creación de los Círculos Metropolitanos de Turismo de Buga, Oriente Antioqueño, Socorro, Villavicencio, Boyacá, Fusagasugá, Norte del Tolima, Occidente de Antioquía, Ipiales, Rionegro-Antioquía y Suroeste Antioqueño; disposición desaparecida en la actual redacción de la Ley operada por la Ley 1.558 de 2012, de 10 de julio, por la cual se modifica la Ley 300 de 1996 -Ley General de Turismo-, la Ley 1.106 de 2006 y se dictan otras disposiciones.

${ }^{21}$ Documento administrativo en el que los conductores de vehículos taxi dejan constancia de las ocasiones en que sobrepasan sus respectivos límites municipales durante el traslado de un cliente.
} 


\section{4. Órganos colegiados con trascendencia turística.}

Los principales órganos colegiados creados por la Ley General de Turismo en este ámbito son el Consejo Superior del Turismo, como órgano de coordinación entre los entes estatales con competencias directas o indirectas en materia turística; el Consejo Consultivo de la Industria Turística, órgano de naturaleza consultiva y funciones de asesoramiento del ejecutivo colombiano en materia de turismo; y el Consejo Nacional de Seguridad Turística, que actúa como instancia de alto nivel desde la cual se consolidan y apoyan los programas que se adelanten en el campo de la seguridad turística.

Junto a éstos, destacan por su singularidad los denominados "Comités locales para la Organización de las Playas", cuya función primordial será establecer en las zonas de playas diferentes franjas destinadas al baño, al descanso, a la recreación, a las ventas de bienes de consumo por parte de los turistas y a la prestación de otros servicios relacionados con las actividades de aprovechamiento del tiempo libre que desarrollen los usuarios de las playas.

\section{Turismo de interés social.}

La Ley colombiana crea el actual sistema de turismo social, denominado "turismo de interés social", para que aquellas familias con menos recursos económicos ${ }^{22}$ puedan disfrutar de su tiempo libre y ejercer su derecho al descanso mediante programas que les permitan realizar actividades de sano esparcimiento, recreación, deporte y desarrollo cultural en condiciones adecuadas de economía, seguridad y comodidad. Para apoyar

22 La última reforma de esta Ley operada en 2012 ha rebajado las exigencias para ser beneficiario de este programa, pasando de entenderse como personas con recursos económicos limitados aquéllas cuyos ingresos familiares mensuales fuesen iguales o inferiores a cuatro salarios mínimos legales mensuales a los dos salarios mínimos que se exigen actualmente. 
esta modalidad turística, la Ley exige que el Plan Sectorial de Turismo recoja necesariamente directrices y programas de apoyo específicos. También se prevé una línea de servicios y descuentos especiales en materia de turismo para la tercera edad, pensionistas, minusválidos y juventud ${ }^{23}$.

La financiación de esta políticas sociales correrá a cargo -parcialmente- del Fondo de Cofinanciación para la Inversión Social (FIS), el cual tendrá como objeto exclusivo cofinanciar la ejecución en forma descentralizada de programas y proyectos presentados por las entidades territoriales, incluidos los que contemplan subsidios a la demanda, en materia de salud, educación, cultura, recreación, deportes, aprovechamiento del tiempo libre y atención de grupos vulnerables de la población. Sus recursos podrán emplearse en programas y proyectos de inversión y gastos de funcionamiento en las fases iniciales del respectivo programa y proyecto, por el tiempo que se determine de acuerdo con la reglamentación que adopte su Junta Directiva. Serán prioritarios, al objeto de su financiación preferente, aquellos programas y proyectos que utilicen el Sistema de Subsidios a la demanda; los orientados a los grupos de la población más pobre y vulnerable, y los que contemplen la constitución y desarrollo de entidades autónomas, administrativas y patrimonialmente para la prestación de servicios de educación y salud.

Para la puesta en marcha de estos programas el Gobierno nacional promoverá la suscripción de acuerdos con los prestadores de servicios turísticos y con las Cajas de Compensación Familiar, por medio de los cuales se determinen precios y condiciones adecuadas, así como paquetes que hagan posible el cumplimiento de los objetivos en materia de turismo social en beneficio de esta población.

\section{Los incentivos tributarios para el fomento de la actividad turística.}

\footnotetext{
${ }^{23}$ En este último caso, las Cajas de Compensación Familiar deberán diseñar programas de recreación y turismo que involucren a la población infantil y juvenil, para lo cual podrán realizar convenios con entidades públicas y privadas que les permitan la utilización de parques urbanos, albergues juveniles, casas comunales, sitios de camping, colegios campestres y su propia infraestructura recreacional y vacacional (art. 36).
} 
Una de las particularidades de esta Ley es que crea una contribución parafiscal con destino a la promoción y competitividad del turismo ${ }^{24}$, a cargo de las empresas y empresarios particulares relacionados con esta actividad en sentido amplio: hoteles, centros vacacionales, clubes sociales, viviendas turísticas, agencias de viajes, operadores turísticos, empresas de turismo de naturaleza y aventura, empresas dedicadas a la organización de congresos, bares y restaurantes turísticos, parques turísticos, concesionarios de aeropuertos y carreteras, empresas de transporte de viajeros no urbano/metropolitano, guías turísticos, etc.

La base para su cálculo serán los ingresos brutos de los obligados a su pago, con un tipo general del 2.5 por mil, rebajado al 1.5 por mil para bares y restaurantes turísticos, y una cuantía fija de 1 US\$ o su equivalente en Pesos Colombianos por pasajero transportado en vuelo internacional con origen o destino final en Colombia. Su recaudación podrá ser delegada por el Ministerio de Comercio, Industria y Turismo a las Cámara de Comercio a cambio de una remuneración determinada reglamentariamente, pasando la cuantía recaudada a conformar el Fondo de Promoción Turística, cuya relevancia ha sido expuesta a lo largo de este estudio. Esta tasa en ningún caso podrá estar sujeta a gravámenes adicionales, tal y como advierte expresamente la Ley colombiana en su art. 41 in fine.

Junto a esta Tasa, la Ley 1.101 de 2006, de 22 de noviembre, por la cual se modifica la Ley 300 de 1996 -Ley General de Turismo- y se dictan otras disposiciones, creó un impuesto con destino al turismo como inversión social, cuyo hecho imponible es el ingreso al territorio colombiano de personas extranjeras en medio de transporte aéreo de tráfico internacional, siendo éstas, asimismo, su sujeto pasivo ${ }^{25}$. Su cuantía es

\footnotetext{
${ }^{24}$ Cuya configuración actual es obra de la Ley 1.101 de 2006, de 22 de noviembre, por la cual se modifica la Ley 300 de 1996 -Ley General de Turismo- y se dictan otras disposiciones.

${ }^{25}$ Están exentos del pago de este tributo (art. 4 de la Ley 1.101 de 2006): a) Los agentes diplomáticos y consulares de gobiernos extranjeros acreditados ante el Gobierno colombiano, y los funcionarios de organizaciones internacionales creadas en virtud de tratados o convenios internacionales suscritos y ratificados por Colombia; b) Los tripulantes de las aeronaves de tráfico internacional y el personal de las líneas aéreas de tráfico internacional, quienes por la naturaleza de su labor deban ingresar a territorio nacional en comisión de servicios o en cumplimiento de sus labores; c) Los estudiantes, becarios, docentes investigadores y personas de la tercera edad; d) Los pasajeros en tránsito en el territorio colombiano; e) Las personas que ingresen a territorio colombiano en caso de arribo forzoso al territorio nacional, incluidos los casos de emergencias médicas producidas a bordo.
} 
12 US\$ o su equivalente en Pesos Colombianos ${ }^{26}$ por turista extranjero, corriendo su recaudación a cargo de las empresas que presten de manera regular el servicio de trasporte aéreo internacional de pasajeros con destino a Colombia. La finalidad última de este tributo será la promoción y competitividad, "de manera que se fomente la recreación y el adecuado aprovechamiento del tiempo libre, de acuerdo con lo previsto en el artículo 52 de la Constitución Política".

Como complemento a lo anterior, la Ley colombiana de turismo prevé la posibilidad de que los Concejos Municipales de aquellos municipios con menos de cien mil habitantes, que posean gran valor histórico, artístico y cultural, establezcan un “peaje turístico" en los accesos a sus sitios turísticos ${ }^{27}$. Los recursos recaudados con este peaje deberán ser destinados exclusivamente a obras de limpieza y ornato o que conduzcan a preservar o mejorar los sitios, construcciones y monumentos históricos del municipio.

Además, el Gobierno Nacional podrá destinar anualmente la recaudación del impuesto de timbre creado por el artículo $14.2 \mathrm{~d}$ ) de la Ley $2^{\mathrm{a}}$ de 1976 (impuesto de timbre para inversión social) para que a través del Ministerio de Comercio, Industria y Turismo se desarrollen programas de inversión social a través de proyectos de competitividad turística, cuyos destinatarios serán las comunidades en condición de vulnerabilidad, los cuales incluirán necesariamente las infraestructuras turísticas.

Por último, la Ley colombiana prevé la devolución a los turistas extranjeros del cien por cien del impuesto sobre las ventas que cancelen por las compras de bienes gravados en el territorio nacional. En relación con este concepto, esta norma prevé que el Gobierno de la Nación deberá destinar anualmente una partida presupuestaria, equivalente por lo menos a la devolución del IVA a los turistas, para que a través del Ministerio de Desarrollo Económico se contraten con la Entidad Administradora del Fondo de Promoción Turística, los programas de competitividad y promoción externa e

\footnotetext{
${ }^{26}$ A partir del 1 de enero de 2012, siendo su cuantía de 5 US\$ hasta el 31 de diciembre de 2008 y de 10 US $\$$ hasta el 31 de diciembre de 2011.

${ }^{27}$ La tarifa que se establezca para el peaje no podrá superar un salario mínimo diario legal por vehículo de uso público o comercial y medio salario mínimo diario legal por vehículo de uso particular (art. 25).
} 
interna del turismo ${ }^{28}$.

\section{El Registro Nacional de Turismo. El concepto de prestador de servicio turístico y sus obligaciones.}

Todos los prestadores de servicios turísticos configurados como tales por la Ley General de Turismo que efectúen sus operaciones en Colombia deben constar inscritos obligatoriamente en el Registro Nacional de Turismo como requisito previo y obligatorio para su funcionamiento (art. 61 párrafo $\left.1^{\circ}\right)^{29}$, cuya gestión puede ser cedida por el Ministerio de Comercio, Industria y Turismo a las Cámaras de Comercio. Para realizar esta función -junto con la citada recaudación de la contribución parafiscal- será necesario que las Cámaras de Comercio garanticen un esquema uniforme de recaudo y un Registro Único Nacional, verifiquen los requisitos previos a la inscripción o renovación del registro y dispongan de un sistema de información en línea para el Ministerio de Comercio, Industria y Turismo.

En este sentido, son prestadores de servicios turísticos, y por lo tanto deberán estar inscritos de forma previa y obligatoria en el Registro Nacional de Turismo, toda persona natural o jurídica que habitualmente proporcione, intermedie o contrate, directa o indirectamente con el turista, la prestación de los servicios a que se refiere esta ley (art. 76). En concreto, la Ley señala que son:

${ }^{28}$ En este sentido, el artículo 40 párrafo segundo señala que La Corporación Nacional de Turismo contratará con el Administrador del Fondo de Promoción Turística, según lo establecido en el artículo $\underline{37}$ de esta ley, la ejecución de programas de promoción que correspondan a la política turística trazada por el Ministerio de Desarrollo Económico, para lo cual destinará no menos del $40 \%$ de su presupuesto de inversión.

${ }^{29}$ Además, como señala la nueva redacción del art. 16 de la Ley 1101 de 2006, dada por la Ley 1558 de 2012: "Únicamente los prestadores de servicios turísticos debidamente inscritos en el Registro Nacional de Turismo podrán ser beneficiarios de los incentivos tributarios y fiscales consagrados a su favor en disposiciones de orden nacional, departamental, distrital o municipal y que tenga por fin estimular, apoyar o promover la actividad turística. La omisión de la actualización del Registro Nacional de Turismo, así como el incumplimiento en el pago de la contribución parafiscal, suspenderá el incentivo tributario correspondiente al año fiscal en el cual se presente la omisión o incumplimiento". 
1. Los hoteles, centros vacacionales, campamentos, viviendas turísticas y otros tipos de hospedaje no permanente, excluidos los establecimientos que prestan el servicio de alojamiento por horas.

2. Las agencias de viajes y turismo, agencias mayoristas y las agencias operadoras.

3. Las oficinas de representaciones turísticas.

4. Los guías de turismo.

5. Los operadores profesionales de congresos, ferias y convenciones.

6. Los arrendadores de vehículos para turismo nacional e internacional.

7. Los usuarios operadores, desarrolladores e industriales en zonas francas turísticas.

8. Las empresas promotoras y comercializadoras de proyectos de tiempo compartido y multipropiedad.

9. Los establecimientos de gastronomía y bares, cuyos ingresos operacionales netos sean superiores a los 500 salarios mínimos legales mensuales vigentes.

10. Las empresas captadoras de ahorro para viajes y de servicios turísticos prepagados.

11. Los concesionarios de servicios turísticos en parque.

12. Los demás que el Ministerio de Comercio, Industria y Turismo determine.

13. Las empresas de transporte terrestre automotor especializado, las empresas operadoras de chivas y de otros vehículos automotores que presten servicio de transporte turístico. 
Pero, además de constar inscritos en el Registro Nacional de Turismo, los prestadores de servicios turísticos deberán cumplir una serie de obligaciones adicionales:

a) Acreditar, ante el Ministerio de Desarrollo Económico, las condiciones y requisitos que demuestren su capacidad técnica, operativa, financiera, de procedencia de capital y de seguridad al turista, así como los títulos o requisitos de idoneidad técnica o profesional correspondientes, de conformidad con la reglamentación que para el efecto expida el Gobierno Nacional, para efectos de su inscripción en el Registro Nacional de Turismo.

b) Ajustar sus pautas de publicidad a los servicios ofrecidos, en especial en materia de precios, calidad y cobertura del servicio.

c) Suministrar la información que le sea requerida por las autoridades de turismo.

d) Dar cumplimiento a las normas sobre conservación del medio ambiente tanto en el desarrollo de proyectos turísticos, como en la prestación de sus servicios.

e) Actualizar anualmente los datos de su inscripción en el Registro Nacional de Turismo.

8. Los prestadores de servicios turísticos previstos en la Ley General de Turismo: parámetros esenciales.

La Ley de turismo de Colombia define a las características esenciales que permiten identificar como tal a de cada prestador de servicios turísticos, además de ciertos requisitos que conforman su naturaleza específica. En cualquier caso, la propia Ley advierte de que para efectos de las definiciones que no están expresamente determinadas en esta ley, se acogerán las formuladas para tal efecto por la Organización Mundial del Turismo (Disposiciones Finales, art. 112). 


\subsection{Establecimientos hoteleros y de hospedaje.}

A diferencia de lo que ocurre en otros países, la Ley colombiana establece un límite temporal para el alojamiento en este tipo de establecimiento: se prohíbe la estancia por tiempo superior a 29 días (inferior a 30 días, en la expresión legal, considerándose como alojamiento privado si excede de este límite). Por otro lado existe libertad para la fijación de los precios de sus servicios: el Ministerio de Comercio, Industria y Turismo se limitará a registrar los precios y tarifas de forma automática, sin que pueda intervenir, controlar o fijar los mismos. No existe, en cualquier caso, una clasificación legal de los establecimientos hoteleros y de hospedaje, que queda en mano-de forma voluntaria- de las asociaciones gremiales, las asociaciones de consumidores y entidades turísticas privadas legalmente reconocidas ${ }^{30}$.

\subsection{Agencias de viajes y de turismo.}

Las agencias de viajes son definidas por la Ley colombiana como aquellas empresas comerciales, constituidas por personas naturales o jurídicas, y que, debidamente autorizadas, se dediquen profesionalmente al ejercicio de actividades turísticas dirigidas a la prestación de servicios, directamente o como intermediarios entre los viajeros y proveedores de los servicios. Existen tres modalidades (a desarrollar reglamentariamente, limitándose la Ley a su mera enumeración, sin definir su

\footnotetext{
${ }^{30}$ Por otro lado, y con independencia del establecimiento de alojamiento turístico de que se trate, el art. 34 de la Ley 1.558 de 2012 impone a los administradores de la propiedad horizontal "[...] de los inmuebles sometidos al régimen de propiedad horizontal en los cuales se preste el servicio de vivienda turística, [la obligación de] reportar al Ministerio de Comercio, Industria y Turismo, la prestación de tal tipo de servicios en los inmuebles de la propiedad horizontal que administra, cuando estos no estén autorizados por los reglamentos para dicha destinación, o no se encuentren inscritos en el Registro Nacional de Turismo. La omisión de la obligación contemplada en este artículo acarreará al administrador la imposición por parte del Ministerio de Comercio, Industria y Turismo de una sanción consistente en multa de hasta 3 salarios mínimos legales mensuales vigentes en el momento del pago, con destino al Fondo de Promoción Turística".
} 
naturaleza o características esenciales): Agencias de Viajes y de Turismo ${ }^{31}$, Agencias de Viajes Operadoras ${ }^{32}$ y Agencias de Viajes Mayoristas ${ }^{33}$.

\subsection{Establecimientos de gastronomía, bares y negocios similares.}

Son, como su nombre indica, aquellos establecimientos cuya actividad económica esté relacionada con la producción, servicio y venta de alimentos y/o bebidas para consumo, además otros servicios complementarios. Como en el caso de los establecimientos hoteleros y de hospedaje, no existe categorización legal, quedando ésta de forma potestativa en manos de la asociación gremial correspondiente, las asociaciones de consumidores y las entidades turísticas privadas legalmente reconocidas.

\subsection{Establecimiento de arrendamiento de vehículos.}

Como señala la Ley colombiana, el contrato de arrendamiento de vehículos -con o sin conductor- es una modalidad comercial de alquiler que una empresa dedicada a esta actividad celebra con el propósito principal de permitir el uso del vehículo a otra persona denominada arrendatario, mediante el pago del precio estipulado. Como ocurre con los establecimientos hoteleros y de hospedaje, existe una total libertad de precios, limitándose el Ministerio de Comercio, Industria y Turismo a registrar los precios y tarifas de forma automática, sin intervenir, controlar o fijar los mismos. Además, los

\footnotetext{
${ }^{31}$ Son las agencias de turismo de carácter minorista, comercializando directamente a nivel de consumidores finales los productos y planes organizados por las agencias de viajes mayoristas.

32 Esta modalidad de agencias de viajes tienen como actividad principal operar planes turísticos, caracterizándose por operar dentro del país planes turísticos programados por agencias del viajes tanto nacionales como extranjeras, organizar y promover planes turísticos para ser operados por ellas mismas, sus sucursales y agencias -si las tuviere-; prestar servicios de transporte turístico y de alquiler de equipos especializados para la práctica de ciertas modalidades turísticas, tales como caza, pesca, equipos deportivos, etc...; y prestar servicios de guianza turística mediante Guías de Turismo debidamente acreditados.

${ }^{33}$ Esta modalidad de agencias de viajes se dedican a la organización de planes/paquetes turísticos que serán ejecutados por las agencias de viajes operadoras y comercializados por las agencias de viajes y turismo, tanto nacionales como de carácter internacional (fuera del territorio nacional), además de reservar y contratar alojamientos y demás servicios turísticos que serán comercializados por las agencias de viajes y turismo.
} 
terminales de transporte y aeropuertos podrán adjudicar en arrendamiento espacios o locales de estos establecimientos con el fin de prestar el servicio de forma eficiente.

\subsection{Empresas captadoras de ahorros para viajes y empresas de servicios turísticos prepagados.}

La Ley General de Turismo se limita a contener su definición, configurándolas como aquellos establecimientos de comercio que reciben pagos anticipados con cargo a programas turísticos que el usuario podrá definir en el futuro.

\subsection{Guías de Turismo.}

Tienen la consideración jurídica de Guías de Turismo a las personas naturales que presten servicios profesionales en el área de guionaje o guianza turística. Sus funciones serán orientar, conducir, instruir y asistir al turista, viajero o pasajero durante la ejecución del servicio contratado. Para ejercer como tal resulta imprescindible poseer la "Tarjeta Profesional de Guía de Turismo" y estar inscrito en el Registro Nacional de Turismo.

Para obtener la tarjeta profesional deberá acreditarse, como mínimo, la posesión del título de formación de educación superior del nivel tecnológico como Guía de Turismo, certificada por el SENA ${ }^{34}$ o por una Entidad de Educación Superior reconocida por el Gobierno Nacional. También podrá ser reconocido como Guía de Turismo quien ostente un título profesional en las áreas afines del conocimiento determinadas por el Ministerio de Comercio, Industria y Turismo, una vez aprobado el curso de homologación que el SENA diseñe para tal fin. Estos últimos solamente podrán ejercer la actividad en el ámbito de su especialidad.

El Estado, por intermediación del SENA o de una Entidad de Educación Superior

\footnotetext{
${ }^{34}$ Siglas del Servicio Nacional de Aprendizaje, entidad pública adscrita al Ministerio de la Protección Social de la República de Colombia.
} 


\section{Doctrina y Jurisprudencia}

reconocida por el Gobierno Nacional, promoverá el desarrollo de competencias en bilingüismo con la finalidad de proporcionar herramientas que permitan el acceso en condiciones de igualdad y equidad a la oferta laboral y empresarial del sector turístico. No obstante, quien obtenga el título profesional de guía de turismo a partir del segundo año de vigencia de la presente ley -1998- deberá acreditar el conocimiento de un segundo idioma.

Los demás prestadores de servicios turísticos tendrán la obligación legal de velar por que los servicios de guianza turística únicamente sean prestados por Guías de Turismo inscritos en el Registro Nacional de Turismo.

\subsection{El sistema de tiempo compartido.}

Por tiempo compartido o time sharing entiende la Ley de turismo colombiana aquel contrato turístico mediante el cual una persona natural o jurídica adquiere, a través de diversas modalidades, el derecho de utilizar, disfrutar y disponer, a perpetuidad o temporalmente, una unidad inmobiliaria turística o recreacional por un período de tiempo en cada año, normalmente una semana.

El legislador colombiano permite que esta modalidad turística se instrumente tanto mediante contratos personales como reales, de conformidad con la naturaleza de los derechos adquiridos, con el único requisito de que, tratándose de derechos reales, éstos deberán observar las formalidades que el Ordenamiento Jurídico exija para su constitución, modificación, afectación y transferencia. Se permite expresamente la constitución de usufructos alternativos o sucesivos, siendo transmisibles mortis causa. Sin embargo, cuando para su instrumentación se acuda al derecho real de dominio o propiedad no procederá la acción de división de la cosa común prevista en su Código Civil (art. 2334), manteniéndose indivisa su propiedad. 
La reglamentación pormenorizada de las modalidades y requisitos relativos a esta modalidad turística, así como de los instrumentos de protección de sus participantes, se remite a un posterior desarrollo reglamentario ${ }^{35}$.

\subsection{Operadores Profesionales de Congresos, Ferias y Convenciones.}

Como en el caso de las empresas captadoras de ahorros para viajes y empresas de servicios turísticos prepagados, la Ley General de Turismo se limita a contener su definición, configurándolas como aquellas personas naturales o jurídicas legalmente constituidas y dedicadas a la organización de certámenes tales como congresos, convenciones, ferias, seminarios y reuniones similares, en sus etapas de gerenciamiento, planeación, promoción y realización, así como a la asesoría y/o producción de estos certámenes en forma total o parcial ${ }^{36}$.

\section{Estatuto jurídico del turista: derecho y obligaciones fundamentales.}

De entre el catálogo de derecho y obligaciones del usuario turístico que recoge la Ley colombiana, muy similar a los existentes en la mayor parte del Derecho comparado, destacan los relativos a la sobreventa (sobrecontratación u overbooking, art. 64), garantizando a aquéllos que cuando los prestadores de servicios turísticos incumplan por sobreventa los servicios ofrecidos o pactados de manera total o parcial, tendrán la obligación a elección del turista, de prestar otros servicios de la misma calidad o de reembolsar o compensar el precio pactado por el servicio incumplido. En tal sentido, ante la imposibilidad de prestar el servicio de la misma calidad, el prestador deberá contratar a sus expensas con un tercero, la prestación del mismo.

\footnotetext{
${ }^{35}$ Realizado por el Decreto 1.076, de 14 de abril de 1997, por el cual se reglamenta el sistema de tiempo compartido turístico.

${ }^{36}$ Desarrollado parcialmente por el Decreto 1.824, de 3 de septiembre de 2001, por el cual se dictan unas disposiciones relacionadas con la actividad de los operadores profesionales de congresos, ferias y convenciones.
} 
En el otro lado de la balanza, ante incumplimientos del usuario turístico (por no presentarse o no utilizar los servicios pactados), el prestador de los mismos podrá exigir a su elección el pago del $20 \%$ de la totalidad del precio o tarifa establecida o retener el depósito o anticipo que previamente hubiere recibido del usuario, si así se hubiere convenido.

Como último hito a destacar, la Ley colombiana habilita un sistema extrajudicial de solución de conflictos en materia turística a elección del turista, que se instrumenta a través de la asociación gremial a la cual esté afiliado el prestador de servicios turísticos contra quien se reclame. Esta asociación gremial propondrá la conciliación entre las partes, que en caso de no resultar posible volverá a la vía administrativa ordinaria, a través de los órganos encargados de velar por los derechos de los consumidores en esta materia. A diferencia de lo que ocurre en otros países, este sistema extrajudicial de solución de conflictos no cuenta con una infraestructura pública para su implementación, sino que utiliza medios propios de unas corporaciones de naturaleza privada como son los gremios turísticos.

\section{La Policía del Turismo.}

Para el cumplimiento de la normativa turística el legislador colombiano crea la "División de Policía del Turismo", ${ }^{37}$, dependiente de la Dirección de Servicios Especializados de la Policía Nacional, y que podrá contar como auxiliares con personas que se encuentren realizando el servicio militar obligatorio en la modalidad de Auxiliar de Policía Bachiller.

\footnotetext{
${ }^{37}$ Entre sus funciones estarán (art. 75 de la Ley General de Turismo): 1. Adelantar labores de vigilancia y control de los atractivos turísticos que, a juicio del Ministerio de Desarrollo Económico y de la Policía Nacional merezcan una vigilancia especial; 2. Atender labores de información turística; 3. Orientar a los turistas y canalizar las quejas que se presenten; 4. Apoyar las investigaciones que se requieran por parte del Ministerio de Desarrollo Económico; 5. Las demás que le asignen los reglamentos
} 